\title{
REDEMOCRATIZAÇÃO E JUSTIÇA DE TRANSIÇÃO NA ARGENTINA E NO PERU: UMA ANÁLISE COMPARADA DAS LEIS DE ANISTIA E DE SEUS JULGAMENTOS PELA CORTE INTERAMERICANA DE DIREITOS HUMANOS
}

\author{
REDEMOCRATIZATION AND TRANSITIONAL JUSTICE IN ARGENTINA AND PERU: \\ A COMPARATIVE ANALYSIS OF AMNESTY LAWS AND THEIR JUDGMENT BY THE \\ INTER-AMERICAN COURT OF HUMAN RIGHTS
}

\author{
David Barbosa de Oliveira \\ Doutor em Direito pela UFPE.Professor adjunto da UFC \\ Professor colaborador do Mestrado e doutorado em Sociologia da UECE \\ E-mail: dvdbarol@gmail.com \\ Recebido em: 03/03/2017 \\ Aprovado em: 31/07/2018
}

\begin{abstract}
RESUMO: Este artigo objetiva realizar uma análise comparada sobre as leis de anistia da Argentina e do Peru. Para tanto lançamos mão de metodologia comparativa. A fim de alcançar os objetivos aqui propostos inicialmente buscamos explanar o método comparado, bem como os pressupostos do direito comparado quanto matéria jurídica. Estabelecido esse ponto de partida, tratamos das leis de anistia da Argentina e do Peru almejando entender as disputas sociais em seu torno. Por fim, investigamos se houve algum reflexo do julgamento da Corte Interamericana de Direitos Humanos sobre as anistias desses países nos seus ordenamentos jurídicos, tendo sempre em vista as disputas e acordos sociais no estabelecimento dessas alterações, buscando estabelecer as diferenças com a justiça transicional brasileira.
\end{abstract}

Palavras-chave: Direito Comparado. Anistia Política. Sistema Interamericano de Direitos Humanos.

\begin{abstract}
This article want to conduct a comparative analysis of the amnesty laws of Argentina and Peru. For this, we use comparative methodology. In order to reach the objectives proposed here initially we seek to explain the comparative method, as well as the assumptions of comparative law as juridical issues. Having established this starting point, we deal with the amnesty laws of Argentina and Peru seeking to understand the social disputes around them. Finally, we investigated whether there was any reflection of the judgment of the Inter-American Court of Human Rights on the amnesties of these countries in their legal systems, always having in mind the disputes and social agreements in the establishment of these alterations, seeking establish the differences with the Brazilian transitional justice.

Keywords: Comparative Law. Political amnesty. Inter-American System of Human Rights.

SUMÀRIO: Introdução. 1 Do método comparado nas ciências sociais ao Direito comparado. 2 Análise comparada das leis de anistia na América do Sul: o caso da Argentina e do Peru. 3 Reflexos dos julgamentos da CIDH nos textos normativos e nas normas internas da Argentina e do Peru. Conclusão. Referências.
\end{abstract}




\section{INTRODUÇÃO}

A anistia é direito que interessa tanto aos nacionais que atravessam crises institucionais, como a transição de um regime autoritário a um democrático, quanto aos sistemas internacionais de proteção dos direitos humanos que podem julgar o Estado ante o descumprimento dos tratados por esse assinado. Assim, podemos dizer que este estudo se relaciona com a Constituição, uma vez que as leis de anistia infraconstitucionais se pautam na previsibilidade material da constituição, firmando seu plano de validade e existência, sendo matéria essencial ao Estado moderno.

Igualmente é certo dizer que o tema anistia também lida de muito perto com as questões dos direitos humanos. Ainda que não haja normatização internacional sobre os limites e legitimidade das leis de anistia, inúmeros julgados da Corte Interamericana de Direitos Humanos tratam do assunto, impondo critérios de legitimidade e limites formais para aceitação das leis, rechaçando as anistias que servem tãosomente para proteger sob a impunidade agressores dos direitos humanos, como demonstram o Caso Barrios Altos, Gomes Lund e Almonacid Arellano.

Desse modo, fica evidente que as leis de anistia dialogam abertamente com os diplomas internacionais de proteção aos direitos humanos e esse fato vincula os Estados, haja vista que, como signatários, submetem-se às cortes em caso de impedimento de investigação, processamento ou julgamento dos agentes do Estado que violaram as normas do tratado ou vilipendiaram os direitos dos presos sob sua responsabilidade. Assim, como afirma Douzinas (2009), os direitos humanos são um discurso e uma prática poderosos no Direito nacional.

Essas considerações nos levam a apensar que o estudo comparado da legislação nacional em conjunto com as práticas do Sistema Interamericano favorece a compreensão de que esses dois sistemas jurídicos (o nacional e o internacional) não se desenvolveram em instâncias apartadas. Pelo contrário, conforme ensina Doehring, "ambas as esferas, a nacional e a internacional, se complementaram e sofreram influências mútuas, no que diz respeito ao surgimento de direitos individuais" (2008, p. 373).

Dito isso, o presente artigo tem o objetivo de dar continuidade a estudos desenvolvidos sobre a Justiça de Transição na América do Sul. Esta justiça, segundo Kai Ambos (2009), compreende os mecanismos e processos da sociedade para enfrentar um legado autoritário de abusos do passado em grande escala, assegurando responsabilidade, justiça e reconciliação, abrangendo a justiça realizada durante a transição de regimes (ditadura para democracia, como in casu), assim como em processos de paz dentro de um conflito em curso. Na Justiça de Transição, a anistia é apenas um dos instrumentos para realizar a transição entre regimes, devendo ser somada a outros que instrumentalizem reparações, investigações, políticas de memória, dentre outros.

Buscamos realizar aqui, especificamente, um estudo comparado entre as leis de anistia da América Latina, bem como observar as consequências do Sistema Interamericano de Direitos Humanos, Comissão e Corte, no direito interno desses países, almejando colaborar e, às vezes, suprir determinadas lacunas que existem nesses estudos no Brasil. Serão analisadas aqui as leis de anistia da Argentina e do Peru, bem como os reflexos nesses países da atuação do Sistema Interamericano. A opção pelo estudo em comparado desses dois países aqui resulta do fato de eles terem sido os que mais avançaram rumo à justiça transicional no continente.

Assim, utilizando pesquisa documental e metodologia eminentemente bibliográfica, analisamos, nos dois países, em um primeiro momento, como as leis de anistia foram gestadas no parlamento, qual seu conteúdo e como essas leis foram recepcionadas pelos militares. Em um segundo momento, buscamos observar como e sociedade civil organizada recebeu essas leis e quais estratégias foram utilizadas junto ao Sistema Interamericano para anular ou revogar tais leis, bem 
como tentar compreender, como a sociedade e o Estado se posicionaram ante as ações da Comissão e da Corte Interamericana de Direitos Humanos.

\section{DO MÉTODO COMPARADO NAS CIÊNCIAS SOCIAIS AO DIREITO COMPARADO}

Antes de adentrarmos no estudo do Direito Comparado, importa fazermos uma breve incursão sobre o método comparado, de modo que possamos abordar depois, mais aprofundamente, as discussões dele decorrente. A comparação, segundo Schneider e Schmitt (1998), enquanto momento da atividade cognitiva, pode ser considerada como inerente ao processo de construção e conhecimento nas ciências sociais. Nesse mesmo sentido, Jolivet (1969) dispõe que a finalidade da comparação é descobrir o que de essencial e, por conseguinte, constante, há no fato social, em contraposição ao que lhe é acidental e provém de particularidades de tempo e de ambiente. Para Schneider e Schmitt,

É lançando mão de um tipo de raciocínio comparativo que podemos descobrir regularidades, perceber deslocamentos e transformações, construir modelos e tipologias, identificando continuidades e descontinuidades, semelhanças e diferenças, e explicitando as determinações mais gerais que regem os fenômenos sociais (1998, p. 49).

A comparação, destarte, aparece como sendo inerente a qualquer pesquisa no campo das ciências sociais, esteja ela direcionada para a compreensão de um evento singular ou voltada para o estudo de uma série de casos previamente escolhidos. Contudo, especificamente, sobre o método comparativo, Koenig (1970), afirma que ele implica comparações de vários tipos de grupos ou povos a fim de desvendar as diferenças e semelhanças em seus modos de vida. A suposição metodológica aqui é que essas divergências e similitudes fornecem chaves importantes para o comportamento social do homem. Daí o motivo pelo qual - conforme aponta Schneider e Schmitt (1998), para Comte, Durkheim e Weber - a análise comparativa está estreitamente relacionada à própria constituição da Sociologia.

Por certo que já encontramos em Conte o método comparativo, haja vista que para ele as leis gerais e invariáveis poderiam ser descobertas na Sociologia por intermédio da comparação (desde que utilizada de modo ordenado e racional), no tempo e no espaço, entre diferentes épocas ou agrupamentos humanos. Contudo, é em Durkheim que a análise comparativa ocupa um lugar central, posto que por seu intermédio ele apresenta a solução para alguns dos problemas fundamentais das ciências sociais como a difícil conciliação entre a complexidade e a generalidade da pesquisa social. Para Durkheim,

não temos senão um meio de demonstrar que um fenômeno é causa de outro, e é comparar os casos em que estão simultaneamente presentes ou ausentes, procurando ver se as variações que apresentam nestas combinações de circunstâncias testemunham que um depende do outro (1998, p. XXI).

É pela comparação entre dois fatos sociais (um crucial e um vulgar) que o sociólogo pode determinar o que é fundamental, estabelecendo a causa principal a partir da qual derivam efeitos e consequências diversas e que, portanto, merece ser investigada. O método sociológico de Durkheim, para Jovilet (1969), expõe, dentre outras coisas, a ideia de que, assemelhado ao método das ciências da natureza, deve tratar os fatos sociais como coisas, para observá-los "de fora" e excluir todas as interpretações psicológicas subjetivas, procurando explicação propriamente sociológica, de tal modo que os fatos sociais se expliquem por outros fatos sociais. Para Durkheim, 
"o social se explica pelo social, as conexões causais fundamentais se desvendam a partir das relações sociais por elas próprias engendradas, e, muitas vezes, não perceptíveis a 'olho nu'” (1998, p. 63).

A comparação desempenha um elemento racional de controle, selecionando as condições suficientes para a realização do fato social, como aponta Fernandes (1980). Estabelecem-se, por ela, os limites para indicar se certos efeitos podem ou não ser atribuídos a determinadas causas. $\mathrm{O}$ método comparativo, então, possibilita que se delimite um campo específico do conhecimento, permitindo que a Sociologia se firme, distanciando-se das outras ciências sociais.

A despeito de qual fosse a razão, o certo é que se buscava - e, por vezes, hoje, ainda se busca - o padrão de civilidade europeu nessas comparações. Em Sociologia, conforme explica Ferreira Pinto (1969), as teorias lineares da evolução social (Comte, Durkheim, Levy-Bruhl, Max Weber, Freud, Pareto etc) abandonam o sistema ptolomaico da história, em proveito do estudo comparado das culturas, em suas diferentes manifestações, e lhes assinalando ciclo vital de nascimento, apogeu e decadência. Para ele, "a teoria linear sugere uma transformação gradual, progressiva e uniforme da sociedade, indicando o melhoramento de formas menos perfeita para mais perfeitos ajustamentos, segunda uma direção bem definida" (1969, p. 172 e 173).

Mais contundente ainda é a posição de Franz Boas sobre a ideia de se utilizar o método comparativo para entender as diferenças de institutos a fim de importá-los, buscando com isso desenvolvimento das estruturas micro e macroeconômicas. Boas aponta censuras ao uso do método comparativo, tal como ele estava sendo aplicado, considerando a história da evolução humana de modo linear. Boas defende que, embora existam similaridades étnicas entre duas ou mais tribos, estas não são, necessariamente, oriundas das mesmas causas, que podem ser tanto internas, fundadas sobre condições psicológicas, quanto externas, baseadas no meio em que elas vivem. Assume ele, portanto, uma visão de evolução multilinear da história, entendendo que o mesmo fenômeno étnico pode surgir independentemente em diversas tribos por diferentes caminhos. Boas (2004) define, então, as regras que o estudo antropológico deve seguir para atingir a galgada segurança. Inicialmente, a investigação detalhada de cada tribo deve ser preliminar a todos os estudos comparativos mais amplos. Além disso, a comparação deve se restringir a apenas os fenômenos que se provem ser efeito das mesmas causas. Portanto, é necessário provar a compatibilidade do material. Deste modo, parece desarrazoada qualquer forma de importação de institutos que almeje desconsiderar a evolução legal e social inerente do local onde será aplicada.

A comparação linear, nesse sentido, busca sempre relacionar culturas, findando por escolher a "melhor", a mais "evoluída", e essa escolha é eurocentricamente determinada. Assim, ante o supra explicado, tivemos sempre o cuidado, nesta pesquisa, de não buscar, no uso desse método, um pretexto para reproduzir soluções coloniais ou mesmo desprovidas de análise crítica.

Estabelecidos esses pressupostos sobre os quais partimos para a realização desse estudo, passamos agora a nos deter mais propriamente ao Direito Comparado. Antes, contudo, importa dizer que ele não é a simples utilização da metodologia comparada, como se poderia se apreender da discussão realizada até agora. O Direito Comparado, segundo Carvalho, "talvez seja um dos raros exemplos em que ocorra uma hipertrofia do método diante do objeto estudado" (2008, p. 142). Essa hipertrofia não favorece o entendimento da matéria. O próprio termo Direito Comparado é consagrado, especialmente, nos países latinos, nos de língua inglesa e nos países escandinavos e eslavos segundo Dantas (2006). Apesar da confusão que o termo e o método carregam consigo, no sentido de se poder imaginar que o Direito Comparado seria um ramo autônomo do Direito, essa expressão é amplamente utilizada no Brasil, sendo entendida como comparação de direitos ou utilização de método comparado. Sobre essa dificuldade terminológica, Carvalho asserta que 
[...] No âmbito do Direito Comparado, todos os métodos utilizados pelos estudiosos são subsídios para a comparação. Ninguém seria ingênuo ao ponto de afirmar que o Direito Comparado, ao desenvolver seu mister, utilizar-se-ia tão-somente do método comparado (2008, p. 142).

Existe no Direito, conforme Pereira (1955), a comparação vertical e a horizontal. Na primeira, o investigador recua no tempo e vai buscar dados informativos do instituto em sua origem, buscando responder como as civilizações anteriores reagiram em face de um determinado problema e qual solução lhes deram, comparando a concepção contemporânea do instituto com os lineamentos do passado, fixando-lhe a linha de evolução que permite configurá-lo no presente e prognosticar as suas tendências no futuro. Na outra, o estudioso estende seu olhar para o horizonte jurídico e focaliza os sistemas atualmente em vigor entre os diversos povos, compara-os, procurando assinalar as suas aproximações e divergências, investigando a amaneira como o mesmo instituto é tratado em outro organismo jurídico, de que modo o legislador de outro país positivou as normas de seu regime, ou como os tribunais as aplicaram e os cientistas as compreenderam. No primeiro caso, temos um exemplo de História do Direito, no outro Direito Comparado. Cláudio Souto é taxativo quanto à distinção entre as duas disciplinas, pois "quaisquer que sejam os serviços que a história comparada possa prestar ao direito comparado dogmático, será um erro confundir estas duas disciplinas. Seus objetos, como seus métodos, diferem radicalmente" (1956, p. 104). Importante ressaltar, entretanto, que, conforme afirma Tavares, "é desaconselhável dissociarem-se tempo e espaço. A história comparativa constitucional caminha junto com o direito comparado, imprimindo a necessária visão dinâmica à pesquisa neste campo" (2009, p. 99).

Por fim, importa ainda dizer que, segundo Serrano (2006), a simples utilização de legislação estrangeira sem se preocupar de detectar semelhanças e diferenças em torno de pontos específicos, não é realizar Direito Comparado. Quando se empreende um estudo de Direito Comparado, sua tarefa vai muito além daquele instante refletido na norma posta, já que deve analisar o quadro geral em que a norma se encontra, inclusive doutrina e jurisprudência, conforme expões Dantas (2006). A comparação, ainda, não deve se ater somente à busca por semelhanças ou diferenças, mas também às causas que as originaram; é necessário averiguar os conceitos fundamentais sobre o qual o sistema está construído. A comparação tem que analisar o Direito em sua totalidade e não apenas no aspecto legislativo a fim de que não se chegue a resultados equivocados. O estudo da legislação alienígena constitui, assim, uma fase preparatória para a compreensão jurídica, mas com ela não se confunde.

Dessa maneira, o Direito Comparado tem por finalidade o aperfeiçoamento do conhecimento, a classificação e agrupamento de ordenamentos, interpretação das instituições constitucionais, preparação da normatização, unificação de direitos e harmonização da norma pluralista, e não a simples comparação entre normas alienígenas. Conforme aponta Serrano, a problemática científica do Direito Comparado "poderá ser vista como o fato, situação ou fenômeno que dá início e estimula o estudo dos elementos comuns que presidem as legislações nacionais e estrangeiras, com o objetivo de facilitar o aperfeiçoamento e aproximação progressiva dos direitos nacionais" (2006, p. 47). Daí porque em seu objeto de estudo, segundo Pereira, "deve ter presente além da legislação, a jurisprudência, conhecimento do meio social, a prática contratual, a tendência da técnica jurídica $(1955$, p. 57)".

Estabelecidos esses pressupostos dogmáticos e metodológicos sobre o Direito Comparado, passamos à análise concreta da legislação de anistia na América do Sul a fim de constatar similitudes e diferenças, de modo que se estabeleçam relações esclarecedoras sobre o instituto e sobre a realidade sociocultural dos países latino-americanos. 


\section{ANÁLISE COMPARADA DAS LEIS DE ANISTIA NA AMÉRICA DO SUL: O CASO DA ARGENTINA E DO PERU}

Os países latino-americanos presenciaram, no contexto da Guerra Fria, a instauração de regimes ditatoriais militares que buscaram a contenção da chamada ameaça comunista e, sob a égide de governos autoritários, milhares de cidadãos foram vítimas de ameaça, exílio, tortura e morte pelos regimes. Com o arrefecimento da ordem bipolar, os países fizeram, pouco a pouco, a sua transição para a democracia e, neste cenário, eram necessários instrumentos legais que possibilitassem uma relativa conciliação entre o passado ditatorial e o presente democrático. A chamada justiça de transição é atualmente o instrumento mais adequado para essas situações, contudo no momento em que a maioria das leis de anistia da América Latina foram feitas, não havia aparato doutrinário ou jurisprudencial que ajudasse na sua feitura. Assim, as leis de anistia, terminaram por conceder perdão aos crimes do período, afetando sua punibilidade e beneficiando tanto os opositores do regime, sem ter qualquer preocupação com verdade, memória ou reparação.

$\mathrm{Na}$ análise comparada das normas de anistia dos países sulamericanos, encontramos elementos similares em várias normas, assim como percebemos alguns elementos que os distinguem no modo de efetivação da pacificação social. Neste trabalho, apresentaremos as leis de anistia da Argentina e do Peru, deixando para outro artigo a análise das leis de: El Salvador, Uruguai, Chile e Brasil. A escolha por esses países, Argentina e Peru, dá-se em razão de eles serem os casos em que houve mais avanços no continente sobre a matéria, bem como um diálogo mais profícuo entre CIDH, sociedade e Estado. Esses dois casos nos ajudam a entender a razão do "sucesso" da transição política nos dois países e é esse o objetivo deste artigo.

Inicialmente, é importante perceber, conforme afirma Perrone-Moisés (2002), que, na Argentina, embora o poder Judiciário tenha sido o ator central na luta contra a impunidade das graves violações aos direitos humanos ocorridas, durante o regime militar, este empenho não foi suficiente para punir os responsáveis pelas atrocidades no período. Em 1983, foi promulgada a Lei de Pacificação Nacional, lei 22.924/83. Essa lei estabelece, em seu artigo 1'o que "declárense extinguidas las acciones penales emergentes de los delitos cometidos con motivación o finalidad terrorista o subversiva, desde el 25 de mayo de 1973 hasta el 17 de junio de 1982"(ARGENTINA, 2016-A). Os benefícios outorgados pela lei se entendem ainda a todos os fatos de natureza penal realizados na ocasião ou com motivo do desenvolvimento de ações dirigidas a prevenir, conjurar ou pôr fim às referidas atividades terroristas ou subversivas, qualquer que tenha sido sua natureza ou bem jurídico lesionado. Os efeitos da lei alcançam aos sujeitos, partícipes, investigadores, cúmplices ou acobertadores e compreende ainda os delitos comuns e militares conexos. $\mathrm{O}$ artigo $5^{\circ}$ da lei declara que ninguém poderá ser interrogado, investigado, citado a comparecer ou requerido de maneira alguma por imputações ou suspeitas de haver cometido delitos ou participado nas ações a que se refere o artigo $1^{\circ}$ acima ou de supor de sua parte conhecimento a respeito deles, de suas circunstâncias, de seus autores, partícipes, instigadores, cúmplices ou encobridores.

Como fazem, em regra, as demais leis de anistia sul-americanas, a Lei da Pacificação exclui certas pessoas ou crimes de seus afeitos. Essa lei punha fora da graça

los miembros de las asociaciones ilícitas terroristas o subversivas que, a la fecha hasta la cual se extienden los beneficios de esta ley, no se encontraren residiendo legal y manifiestamente en el territorio de la Nación Argentina o en los lugares sometidos a su jurisdicción o que por conductas hayan demostrado el propósito de continuar vinculados con dichas asociaciones (ARGENTINA, 2016-A). 
A lei ainda excluiu, em seu artigo $8^{\circ}$, a possibilidade de punição nas causas que investiguem fatos cujos autores sejam militares ou policiais, posto que dispôs em seu texto que se encontram compreendidas no alcance da lei as causas "en trámite o sobreseídas provisionalmente, en las cuales se investiguen hechos cuyos autores aún no hayan sido individualizados y se les atribuya el carácter de integrantes de las Fuerzas Armadas, de seguridad o policiales, o se exprese que los mismos invocaron algunos de estos caracteres"(ARGENTINA, 2016-A). A exclusão da anistia também se aplica quando se houvesse alegado a condição de terrorista ou manifestado que atuavam por uma força aparentemente irresistível.

Afirma Nino que "casi todos los setores políticos junto con los grupos de derechos humanos rechazaron la ley, excepto los de la extrema derecha" (2015, p. 134). Por isso, o presidente eleito Raúl Alfonsín, ainda quando candidato, ao contrário de seu oponente na disputa, denunciou, durante sua campanha, a existência de um pacto sindical-militar na gestação da Lei da Pacificação Nacional e prometeu deixá-la sem efeito. Ainda antes de assumir, enviou ao Congresso um projeto de lei para derrogá-la, o qual foi aprovado uma semana depois, era a lei n. $^{\circ}$ 23.040. A referida lei dispunha, já em seu artigo $1^{\text {o: }}$ "derógase por inconstitucional y declárase insanablemente nula la ley de facto $N^{o} 22.924$ (ARGENTINA, 2016-B). Em seu artigo segundo, afirmava que a referida lei carecia de "efecto jurídico para el juzgamiento de las responsabilidades penal, civil, administrativa y militar emergentes de los hechos que ella pretende cubrir, siendo en particular inaplicable a ella el principio de la ley penal más benigna" (ARGENTINA, 2016-B). Exigia a lei, inclusive, que quem tivesse sido posto em liberdade em decorrência da lei 22.924 deveria apresentar-se ante o tribunal da causa em cinco dias, do contrário seria declarado rebelde e se poderia haver sua captura sem citação prévia.

Assim que derrogaram a Ley de Pacificación Nacional o Ministério da Defesa de Raúl Alfonsín, segundo Nino (2015), comunicou oficialmente ao Conselho Supremo das Forças Armadas o processamento contra nove membros integrantes das três primeiras juntas militares, levando a condenação de prisão perpétua: Jorge Rafael Videla (ocupou a presidência de 1976 a 1981) e de Emilio Eduardo Massera (integrou a junta que instaurou a ditadura militar no país), bem como a prisão de Roberto Eduardo Viola, de Armando Lambruschini e de Orlando Ramón Agosti (todos também integrantes da junta militar que instaurou a ditadura militar argentina), respectivamente há 17, 8 e 4 anos. É importante perceber, conforme apontam Battistessa e Zurita, que "las decisiones tomadas por el presidente Raúl Alfonsín (1983-1989), los ministros de Defensa y de Relaciones Exteriores, junto al resto de los funcionarios estuvieron mediadas por una 'negociación constante' con las Fuerzas" (2014, p. 38).

Contudo, a construção da anistia, entre os países latinoamericanos, não obedece uma linearidade progressiva, sendo feita de idas e vindas. Seguindo essa sina, a partir de 1986, foram feitas novas leis de anistia que buscaram novamente anistiar os militares. O governo encabeçado de Raúl Alfonsín tentou aproveitar o consenso adquirido pelas urnas e adotar uma série de medidas para democratizar as Forças Armadas, contudo de acordo com Morales, "como era de esperarse, las medidas de castigo a las violaciones a los derechos humanos cometidas en el pasado generaron la oposición de los afectados" (2005, p. 206). Assim, dentro desse movimento, editou-se a chamada "Lei Ponto Final" (Lei 23.492), que determinava "la extinción de acciones penales por presunta participación, en cualquier grado vinculado a la instauración de formas violentas de acción política" (ARGENTINA, 2016-C). Posteriormente, em 1987, foi editado novo instrumento anistiador: a "Lei Obediência Devida" (Lei 23.521). A lei da Obediencia Devida, segundo Morales, "creó la presunción irrebatible a favor del personal militar que cometió crímenes de haber actuado en virtud del deber de obediencia, eximiéndolos de responsabilidad penal" (2005, p. 206). Além 
dessas, o novo presidente, Carlos Menem, conforme sustenta Hunter (1997), concedeu ainda uma série de indultos aos militares já condenados, um enorme retrocesso ante os esforços realizados, pelo presidente anterior, para processar e punir os responsáveis pelos crimes do regime militar.

Mas a disputa pelo texto legal não quedou assim por muito tempo. Tanto a lei 23.492 quanto a lei 23.521, tiveram sua validade novamente posta em cheque no ordenamento argentino. Em um novo esforço de punir os militares que excederam os limites da lei e violaram a dignidade de argentinos, estas leis de anistia foram derrogadas, em 1998, pela lei 24.952 (ARGENTINA, 2016-D), e, mais a frente, anuladas, em 2003, pela lei 25.779 (ARGENTINA, 2016-E).

No Peru, o governo de Fujimori, de duvidosa legitimidade democrática, tanto de origem como de exercício, produziu duas leis que trataram do regime jurídico do anistiado: a lei $\mathrm{n}^{\circ} 26.479$ e a lei $\mathrm{n}^{\circ} 26.492$, ambas de 1995. A lei peruana se dirige aos agentes militares ou civis e alcança "todos los hechos derivados u originados con ocasión o como consecuencia de la lucha contra el terrorismo" (PERU, 2016-A), excluindo totalmente os que não estavam na defesa do status quo. Todos os artigos da lei blindam de qualquer investigação ou responsabilização os agentes estatais, pois concedia anistia geral ao pessoal Militar Policial ou Civil: "cualquiera que fuere su situación Militar o Policial o Funcional correspondiente, que se encuentre denunciado, investigado, encausado, procesado o condenado por delitos comunes y militares en los Fueros Común o Privativo Militar, respectivamente" (PERU, 2016-A). A lei deixava claro que a anistia alcançava "al personal militar en situación de Actividad, Disponibilidad o Retiro y civil implicados, procesados o condenados por los sucesos del 13 de Noviembre de 1992" (PERU, 2016-A), bem como "al personal militar en situación de Actividad, Disponibilidad o Retiro denunciado, procesado o condenado por los delitos de Infidencia, Ultraje a la Nación y a las Fuerzas Armadas, con ocasión del reciente conflicto en la frontera norte" (PERU, 2016-A).

O Poder Judiciário, no chamado foro comum e militar, e o Executivo anularão os antecedentes policiais, judiciais ou penais que pudessem ser registrados contra os anistiados assim como deixam sem efeito qualquer medida restritiva de liberdade que possam os afetá-los. "Procederán igualmente a excarcelar a los amnistiados que estuvieran sufriendo arresto, detención, prisión o pena privativa de la libertad, quedando subsistentes las medidas administrativas adoptadas" (PERU, 2016-A). O artigo $5^{\circ}$ da lei exclui da anistia o agente "Militar, Policial o Civil que se encuentra denunciado, investigado, encausado o condenado por los delitos de Tráfico Ilícito de Drogas, de Terrorismo y Traición a la Patria" (PERU, 2016-A). Vedou ainda qualquer tipo de investigação ao afirmar no artigo $6^{\circ}$ que os delitos compreendidos na lei não são suscetíveis de investigação, pesquisa ou sumério, restando todos os casos judiciais, em trâmite ou em execução, arquivados definitivamente.

A lei 26.492, do mesmo ano, vem estabelecer o alcance hermenêutico da lei anterior de anistia. Afirma essa lei que a anterior não constitui interferência no exercício do judiciário nem vulnera o dever do Estado de respeitar e garantir os direitos humanos, "reconocido por el artículo $44^{\circ}$ de la Constitución Política y, entre otros Tratados sobre la materia, el numeral $1^{\circ}$ del artículo $1 o$ de la Convención Americana sobre Derechos Humanos" (PERU, 2016-B). O artigo $2^{\circ}$ da lei reforça que a anistia cuja concessão corresponde exclusivamente ao Congresso não é revisável pelo judiciário. $\mathrm{O}$ artigo $3^{\circ}$ dispõe que o artigo $1^{\circ}$ da lei $\mathrm{n}^{\circ} 26.479$ deve ser interpretado "en el sentido que la amnistía general que se concede es de obligatoria aplicación por los Organos Jurisdiccionales y alcanza a todos los hechos derivados u originados con ocasión o como consecuencia de la lucha contra el terrorismo cometidos en forma individual o en grupo" (PERU, 2016-B) de maio de 1980 até 14 de junho de 1995, sem importar que o pessoal militar, policial ou civil se encontre ou não denunciado, investigado, sujeito a processo penal ou condenado; quedando todos os casos judiciais em trâmite ou em execução arquivados definitivamente em conformidade 
com o artigo $6^{\circ}$ da lei de anistia peruana. Interessante perceber que a expressa referência a Convención Americana sobre Derechos Humanos, artigo $1^{\circ}$, a lei não respeitava a convenção como veremos no tópico seguinte.

Assegura Canton (2007) que "el escándalo de los videos de Vladimiro Montesinos" (vídeos que mostram como Vladimiro Montesinos - acessor presidencial de Alberto Fujimori - subornava a dirigentes políticos, de empresas privadas importantes, de comunicação e governos locais), a pressão da comunidade internacional e a mobilização da sociedade civil peruana acelerou a queda do regime de Fujimori. Assim, o desprestigio do setor civil-militar do regime de FujimoriMontesinos findou similar ao dos militares argentinos, permitindo que a sociedade civil pudesse avançar mais na persecução penal dos agentes de repressão que violaram direitos humanos.

Por fim, percebe-se, que nenhuma dessas anistias se pretendeu absoluta, posto que todas excluem um tipo penal ou um grupo de pessoas do esquecimento. Ao mesmo tempo, todas são consideradas autoanistia, ou melhor, anistia incondicionadas, que não se abrem para a possibilidade de responsabilização civil, penal ou administrativa, conforme preceitua a moderna Justiça de Transição que será mais à afrente abordada. Em todas as leis, um determinado grupo de pessoas ou condutas são excluídas da anistia e poderão ser investigadas, processadas, julgadas e punidas.

\section{REFLEXOS DOS JULGAMENTOS DA CIDH NOS TEXTOS NORMATIVOS E NAS NORMAS INTERNAS DA ARGENTINA E DO PERU}

Nessa seção, nosso escopo é observar como o ordenamento jurídico interno reagiu aos julgamentos da CIDH no tocante às leis de anistia. Assim observaremos como o sistema jurídico da Argentina e do Peru responderam à jurisprudência da Corte, observando se o sistema transnacional é coerente e consistente, ou se há contradições entre os sistemas da CIDH e dos tribunais nacionais.

$\mathrm{Na}$ Argentina, como aponta Slumovitz, "la centralidad que adquirió la cuestión de los derechos humanos y la demanda de justicia determino la emergencia de un espacio institucional en donde su accionar aparecia como necesario para reinstalar el imperio de la ley y evitar así la repetición de los horrores del pasado" (1995, p. 95). Talvez por isso em poucos casos pôde se ver com tanta clareza o impacto do Sistema Interamericano de Proteção de Direitos Humanos no ordenamento interno. A grande quantidade de denúncias recebidas da Argentina, nos anos setenta, e o tipo de violações denunciadas aí foi um dos fatores que levou a $\mathrm{CIDH}$ a realizar uma visita àquele país em 1978. Dessa visita, segundo Nino, a Comissão Interamericana publicou "un reporte que contenía una seria condena al régimen militar argentino" (2015, p. 127). Esse reporte difundiu pelo mundo as violações massivas e sistemáticas cometidas pela ditadura argentina e obrigou o governo militar a responder internacionalmente por elas.

Explica Canton (2007) que, as denúncias, a visita in loco e o reporte possibilitou que, anos depois, as vítimas de violações dos direitos humanos recorressem novamente à Comissão para que esta decidisse sobre a compatibilidade das leis de anistia com a Convenção Americana. A partir de 1987, a Comissão começou a receber petições que denunciavam que as leis de anistia violavam a Convenção Americana de Direitos Humanos. A Comissão, em 1989, após evasiva resposta do governo argentino a estas denúncias, recomendou, por meio do informe 28/92 (COMISSÃO INTERAMERICANA DE DIREITOS HUMANOS, 2016), esclarecer os fatos e individualizar os responsáveis pelas violações ocorridas durante a ditadura militar. Contudo, o governo de Carlos Menem não seguiu as recomendações da Comissão.

Em 1996, a partir de declarações públicas de oficiais das forças armadas que reconheciam as violações ocorridas durante a ditadura, a Comissão celebrou algumas audiências que retomaram 
as denúncias anteriores e assim estabeleceu-se um importante espaço de diálogo entre a sociedade civil e o Estado. Em 1995, a senhora Carmen Aguiar de Lapacó e outras organizações de direitos humanos apresentaram uma petição à Comissão, segundo expõe Burt (2011), arguindo a rejeição das autoridades argentinas de sua solicitação para conhecer o que ocorreu com sua filha Alejandra Lapacó. Em 1998, a CIDH admitiu a petição e se pôs à disposição das partes para iniciar una solução amistosa (COMISSÃO INTERAMERICANA DE DIREITOS HUMANOS, 2017-A). Como resultado desse diálogo, o governo se comprometeu a: a aceitar e garantir o direito a verdade, esgotando todos os meios para alcançar o esclarecimento sobre o sucedido com as pessoas desaparecidas; todos os casos de averiguação da verdade passaram a ser de competência exclusiva de Câmaras Nacionais, gerando maior coerência nas decisões; destacar dentro do Ministério Público um corpo de fiscais ad hoc para as causas de busca da verdade e de pessoas desaparecidas (COMISSÃO INTERAMERICANA DE DIREITOS HUMANOS, 2017-B).

Todos esses esforços ajudaram para que, quando a discussão sobre a validade da lei de anistia chegasse à Corte Suprema de Justiça, em 2005, o caso impetrado, pelo Centro de Estudios Legales y Sociales (CELS) sobre a "desaparición del matrimonio Poblete", pudesse ser revogado as leis de anistias. A Corte entendeu que as leis de

obediencia debida y punto final" fossem "inaplicables a estos delitos porque no los contemplaron o, de ser aplicables, son inconstitucionales, porque si los contemplaron, violaron el derecho internacional consuetudinario vigente al tiempo de su promulgación (...) aquellas leyes [obediencia debida y punto final] son inaplicables a los delitos de lesa humanidad o son inconstitucionales si fuesen aplicables a los delitos de esa laya. En ambas hipótesis resultan inaplicables (ARGENTINA, 2017).

A decisão ratificava, segundo Miguel Arenas Meza, "las decisiones de tribunales inferiores que habían declarado inconstitucionales las referidas leyes y avalaba a su vez, la Ley 25.779 del Congreso Nacional, que anulaba dichas leyes" (2010, p. 196). A decisão afirma que com as leis de anistia o Estado sofreu limitações ante sua obrigação de garantir os direitos contidos na Convenção Americana sobre Direitos Humanos (art. 1.1.) e no Pacto Internacional de Direitos Civis e Políticos. Ainda segundo Meza, "en esta sentencia se puso claramente de manifiesto la importante influencia de la jurisprudencia de la Corte interamericana en los fallos y decisiones de los Tribunales internos" (2010, p. 196), demonstrando o grande impacto que as práticas e textos do Sistema Interamericano tiveram sobre o ordenamento argentino.

Peru é outro caso em que houve grande repercussão do Sistema interamericano (Comissão e Corte) em seu ordenamento jurídico. Em particular, esse é relevante porque pela primeira vez um caso sobre a compatibilidade das leis de anistia com a Convenção Americana chega à CIDH. Para Abramovich, a visita da CIDH ao Peru em 1992, e depois em 1999, e seu relatório sobre “'democracia e direitos humanos', junto com as sentenças paradigmáticas da Corte sobre legislação antiterrorista, liberdade de expressão e tribunais militares, contribuíram para documentar e expor a gravidade das violações cometidas durante esse período" (2009, p. 24). Esta tanto levou ao conhecimento da comunidade internacional o que aconteceu no Peru, quanto fortaleceu os organismos de direitos humanos locais, constantemente desacreditados por ambos regimes. Assim, o caso argentino e o peruano têm em comum o fato de a CIDH desempenhar um papel destacado nos na justiça de transição desses países.

No início dos anos 90, a Comissão começou a receber denuncias sobre execuções extrajudiciais e desaparecimentos forçados. Dessa, os casos de La Cantuta y Barrios Altos (que 
inclusive foi citado na decisão da Corte Argentina) são emblemáticos para o Sistema Interamericano, por seus efeitos no processo político interno peruano. O Caso Barrios Alto findou com a Corte entendendo que são inadmissíveis as disposições de anistia, as disposições de prescrição e o estabelecimento de excludentes de responsabilidade que pretendam impedir a investigação e sanção dos responsáveis das violações graves dos direitos humanos, senão vejamos:

41. Esta Corte considera que son inadmisibles las disposiciones de amnistía, las disposiciones de prescripción y el establecimiento de excluyentes de responsabilidad que pretendan impedir la investigación y sanción de los responsables de las violaciones graves de los derechos humanos tales como la tortura, las ejecuciones sumarias, extralegales o arbitrarias y las desapariciones forzadas, todas ellas prohibidas por contravenir derechos inderogables reconocidos por el Derecho Internacional de los Derechos Humanos (CORTE INTERAMERICANA DE DIREITOS HUMANOS, 2016-A).

A Corte, então, resolveu "declarar que las leyes de amnistía 26.479 y 26.492 eran incompatibles con la Convención Americana sobre Derechos Humanos y carecen de efectos jurídicos" (CORTE INTERAMERICANA DE DIREITOS HUMANOS, 2016-A). Mesmo que a Corte se refira em algumas partes da sentença as leis de anistia e em outras às leis de autoanistia, segundo Canton, fica evidente que "la incompatibilidad con la Convención Americana existe en cualquiera de los dos casos, siempre y cuando se den los requisitos que impidan la investigación y sanción de los responsables de las violaciones graves de los derechos humanos" (2017, p.154).

A Corte deixa claro que nem tudo o que é legal do ponto de vista interno também o é sob o prisma internacional. Assim, a Corte fulminou as leis de anistia, pois entendeu que estas careciam de qualquer efeito jurídico, atentando, a um só tempo, ao direito da vítima à justiça e à verdade. Ademais, considerou-se que essas leis são, em sua essência, incompatíveis com a Convenção Americana, pois favorecem a impunidade e a injustiça. Cançado Trindade, em seu voto, indaga saber quem ousaria sugerir que essas leis satisfazem esses requisitos? E afirma

\footnotetext{
Não vejo como negar que leis desse tipo carecem de caráter geral, porquanto são medidas de exceção. E certamente em nada contribuem para o bem comum, senão pelo contrário: configuram-se como meros subterfúgios para encobrir violações graves de direitos humanos, impedir o conhecimento da verdade e obstaculizar o próprio acesso à justiça por parte dos vitimados. Em suma não satisfazem os requisitos de leis no âmbito do Direito Internacional dos Direitos Humanos (2002, p. 89).
}

Segundo Canton (2007), o governo de Fujimori não tinha nenhuma vontade política de cumprir com as recomendações da Comissão ou das decisões da Corte. O governo buscava, a todo momento, limitar a capacidade do Sistema Interamericano, tanto que, em 8 de julho de 1999, publicou-se a resolução legislativa que retirou o reconhecimento da competência contenciosa da CIDH. Ante esse fato, a Corte resolveu que "el pretendido retiro, con efectos inmediatos, por el Estado peruano, de la declaración de reconocimiento de la competencia contenciosa de la Corte Interamericana de Derechos Humanos es inadmisible" (CORTE INTERAMERICANA DE DIREITOS HUMANOS, 2016-B). Apenas com a saída do governo Fujimori se retomou o diálogo com o Sistema Interamericano. Segundo Canton, "tanto el Gobierno de Valentín Paniagua como el de Alejandro Toledo sostuvieron en todo momento un diálogo con la Comisión y la sociedad civil orientado a cumplir las recomendaciones" (2007, p. 167). Para Abramovich, "o pleno retorno 
do Peru ao SIDH em 2001 e a aceitação da responsabilidade internacional pelos crimes atrozes do regime de Fujimori compuseram uma política essencial do governo de transição" (2009, p. 24). Assim, os governos posteriores optaram por cumprir a decisão da CIDH, dispondo que todos os fiscais que tenham intervido em processos nos quais se aplicaram leis de anistia, devem solicitar aos respectivos juízes a execução da sentencia da CIDH.

A decisão da Corte sobre o caso Barrios Altos foi confirmada em vários procedimentos legais no Peru, incluindo uma decisão do Tribunal Constitucional, que tornou possíveis os processos criminais por violações de direitos humanos. Em 22 de setembro de 2005, a CIDH decidiu "que la obligación de dar efecto general a la declaración de ineficacia de las leyes 26.479 y 26.492 ha sido cumplida por el Estado" (CORTE INTERAMERICANA DE DIREITOS HUMANOS, 2017-B). Uma série de outras condenações foram proferidas, entre 2006 e 2008, em casos emblemáticos, incluindo o desaparecimento de autoridades públicas em Chusci e o desaparecimento do jornalista Hugo Bustíos. Em 2008, o ex-líder do Sistema de Inteligência Nacional (SIN), Julio Salazar Monroe, foi condenado por seu papel nos desaparecimentos e assassinatos, em 1992, de estudantes e de um professor da Universidade La Cantuta. Em 2009, segundo Engstrom (2011), entendendo a Suprema Corte que Alberto Fujimori tinha sido responsável pelas mortes e desaparecimentos causados por uma unidade militar que estava sob seu comando, ratificou unanimemente o veredito contra o então presidente de uma pena de 25 anos de prisão. O julgamento de Fujimori e seu veredicto, segundo Burt (2011), foram considerados pelo direito internacional e por especialistas em direitos humanos como um processo legal impecável, um divisor de águas nos esforços contra a impunidade no Peru e no resto do mundo.

Por fim, conforme explica Burt (2011), embora o Tribunal Constitucional do Peru tenha afirmado que o direito internacional deve ser considerado pelos tribunais peruanos nos julgamentos de casos de direitos humanos, em vários casos recentes, os juízes têm ignorado ou revisado estes precedentes absolvendo os acusados. Estas tendências não são incidentes isolados, ocorreram no contexto da interferência política no processo de judicialização durante o governo García, que parece ter sido concebido para travar os esforços de responsabilização no Peru. Além disso, houve repetidos esforços para aprovar leis de anistia que encerrariam os julgamentos de direitos humanos.

\section{CONCLUSÃO}

O locus, dentro do estudo dos direitos humanos, como dissemos anteriormente, dessa pesquisa, é a Justiça de Transição. Nessa justiça, que se ocupa de mecanismos e processos para enfrentamento de legados autoritários em grande escala, a anistia é apenas um dos instrumentos para realizar a transição entre regimes, devendo ser somada a outros que instrumentalizem reparações, investigações, políticas de memória etc. Nesse contexto, deve-se afastar a ideia de anistia absoluta ditada pela tradicional e histórica ideia de esquecimento dos fatos e priorizar as anistias condicionadas, haja vista não eximirem automaticamente de punição os atos cometidos.

Contudo, não foi isso que vimos no estudo comparado das leis de anistia da Argentina e do Peru. Em verdade, a realidade que é imposta pela América Latina é a do uso de leis de anistia como subterfúgio para impunidade penal. As leis de anistias estudadas não tiveram nenhuma preocupação em responsabilizar os agentes do Estado que violaram a dignidade das vítimas, pelo contrário, almejaram pôr os agentes sob o manto do esquecimento, crendo que isso pacificaria a sociedade. Assim, as leis se vincularam à clássica visão do instituto, sendo a anistia o "manto do eterno esquecimento" (BARBOSA, 1896), estando afastada da ideia de justiça transicional.

Percebemos ainda que, a despeito das leis publicadas no processo de redemocratização desses países terem sido anistias absolutas, a sociedade civil organizada e não organizada em 
diálogo com o Sistema Interamericano de Direitos Humanos conseguiram tencionar os agentes políticos e o sistema jurídico de modo a disputar não só a formação da norma jurídica, mas o próprio texto legal. Deste modo, não podemos deixar de perceber que, em ambos os casos, o processo de redemocratização foi tenso, que a disputa pelo texto legal e sua interpretação não foi pacífico e que não houve, durante esse processo, um consenso sobre o perdão dos agentes do Estado. As idas e vindas, nesse processo, envolveram os três poderes, mas o que foi imperioso para os avanços sociais foi a utilização por um relevante conjunto da sociedade da Comissão e da Corte Interamericana.

Um último ponto que temos que destacar, neste estudo, foi a repercussão que os julgamentos da CIDH tiveram sobre os ordenamentos jurídicos da Argentina e do Peru. O uso do Sistema Interamericano fez com que os direitos humanos fossem amplamente adotados pelos agentes do judiciário, ocupando, nesses países, um espaço do que no Brasil é adotado pelos direitos fundamentais. Percebemos que o Sistema Interamericano junto com a sociedade civil organizada fomentou alterações no ordenamento interno desses países. Podemos até dizer, indo além, que foram o sustentáculo dessa alteração, tendo inclusive servido, como vimos, na fundamentação de decisões das Cortes jurídicas desses países.

Percebemos que o Brasil, ante o intenso debate realizado, na Argentina e no Peru, entre Estado, sociedade e Sistema Interamericano de Direitos Humanos, não realizou a devida discussão sobre suas anistias e justiça de transição. O texto da anistia brasileira e seu sentido foram determinados deixando algumas minorias de fora como se deu com os militares cassados. Outro elemento que resta claro é a diferença no exercício do poder, durante a transição democrática, nas mãos dos militares brasileiros e nos outros dois países. Ao contrário dos militares argentinos e peruanos, os brasileiros exerceram intensa influência durante a transição democrática, tanto que o ministro do Exército, Leônidas Pires Gonçalves, teria dito, durante os debates da Constituinte, que "não se responsabilizaria por possíveis revoltas nos quartéis caso passasse a anistia" (CORREIO BRASILIENSE, 1987, p. 6). Não há como imaginar qualquer responsabilização dos militares brasileiros se ainda detinham tanto poder nas mãos.

Percebemos ainda que tanto na Argentina quanto no Peru também houve intensa disputa pelo sentido da anistia, mas, ao contrário do Brasil, percebemos maior participação social e um judiciário aberto ao diálogo com outros sistemas jurídicos, não se estabelecendo como único detentor da verdade. Esse diálogo poderia evitar, por exemplo, o descompasso entre o debate, dentro e fora do país, sobre anistia, bem como o fato de o STF ter entendido que a Lei de 1979 foi recepcionada pela Constituição Federal de 1988 ao mesmo tempo em que a CIDH afirmou que a Lei fere a Convenção Interamericana de Direitos Humanos. Entendemos que a decisão do Supremo possui inconsistências, incoerências e erros argumentativos como, por exemplo, a utilização equivocada de conceitos e jurisprudência da Corte Interamericana de Direitos Humanos o que já apresentamos em outro artigo.

Por fim entendemos que esse estudo demostrou o caráter utópico dos Direitos Humanos. Utópico porque permite apresentar que há ainda nesses direitos algo que os deixa, como afirma Douzinas, em "um lugar desconfortável no texto da lei, nacional ou internacional” (2009, p. 373). O esvaziamento político do conteúdo dos direitos humanos e a hipertrofia de sua normatividade retira deles seu aspecto emancipador, tornando-o em mais um instrumento de regulação da sociedade. Assim, ainda com Douzinas, podemos perceber que "os direitos humanos representam a necessária e impossível reinvindicação de lei e de justiça” (2009, p. 383). É o caráter utópico desses direitos, e não o normativo, que lhe possibilita fazer a crítica e resistir às ações que impedem o pleno desenvolvimento humano como vimos na disputa pela anistia na Argentina e no Peru. 


\section{REFERÊNCIAS}

ABRAMOVICH, Víctor. Das violações em massa aos padrões estruturais: novos enfoques e clássicas tensões no Sistema Interamericano de Direitos Humanos. SUR. v. 6, n. 11, dez. 2009. p. 7-39.

AMBOS, Kai. Justicia de transición: informes de América Latina, Alemania, Italia y España. AMBOS, Kai; MALARINO, Ezequiel e ELSNER, Gisela (Orgs). Justicia de transición: informes de América Latina, Alemania, Italia y Españna. Montevideo: Konrad-Adenauer-Stiftung, 2009.

ARGENTINA. Ministerio da Justicia e Derechos Humanos. Ley de Pacificación Nacional N ${ }^{\circ}$ 22.924. Disponível em:

<ttp://abc.gov.ar/docentes/efemerides/10dediciembre/site_10diciembre/descargas/elproceso/leypa cificacion.pdf $>$. Acesso em: 11 jul. 2016. A

ARGENTINA. Ministerio da Justicia e Derechos Humanos. Ministerio da Justicia e Derechos Humanos. Ley 23.040. Disponível em:

<http://servicios.infoleg.gob.ar/infolegInternet/anexos/25000-29999/28166/norma.htm>. Acesso em: 11 jul. 2016. B

ARGENTINA. Ministerio da Justicia e Derechos Humanos. Ministerio da Justicia e Derechos Humanos. Lei 23.492. Disponível em:

<http://servicios.infoleg.gob.ar/infolegInternet/anexos/20000-24999/21864/norma.htm>. Acesso em: 01 fev. 2016.C

ARGENTINA. Ministerio da Justicia e Derechos Humanos. Ministerio da Justicia e Derechos Humanos. Lei 24.952. Disponível em:

<http://servicios.infoleg.gob.ar/infolegInternet/anexos/50000-54999/50364/norma.htm>. Acesso em: 01 fev. 2016. D

ARGENTINA. Ministerio da Justicia e Derechos Humanos. Ministerio da Justicia e Derechos Humanos. Lei 25.779. Disponível em:

<http://servicios.infoleg.gob.ar/infolegInternet/anexos/85000-89999/88140/norma.htm>. Acesso em: 01 fev. 2016. E

ARGENTINA. Ministerio da Justicia e Derechos Humanos. Presidencia de la Nación. Ministerio de Justicia y Derechos Humanos. Disponível em:

<http://www.biblioteca.jus.gov.ar/fallosimon.html>. Acesso em: 31 jan. 2017.

BARBOSA, Rui. Anistia inversa. Caso de Teratologia Jurídica. 2. ed. Rio de Janeiro: Typ. do Jornal do Comércio, 1896.

BATTISTESSA, Gregorio J. Dolce e ZURITA, María Delicia. Argentina y Brasil civiles y militares: tres décadas de convivencia en perspectiva comparada. Revista Cantareira - Edição 20/Jan-Jun, 2014, pp. 37-51.

BOAS, Franz. Antropologia Cultural. Org. Celso Castro. Rio de Janeiro: Jorge Zahar, 2004. 
BURT, Jo-Marie. BURT. Desafiando a impunidade nas cortes domésticas: processos judiciais pelas violações de direitos humanos na América Latina. In: REÁTEGUI, Félix (Org.). Justiça de transição: manual para a América Latina. Brasília: Ministério da Justiça, 2011.

CANTON, Santiago A. "Leyes de amnistía". Víctimass in mordaza. El impacto del Sistema Interamericano en la Justicia Transicional en Latinoamérica: los casos de Argentina, Guatemala, El Salvador y Perú. Washington, D.C. México: Due Process of Law Foundation; Comisión de Derechos Humanos del Distrito Federal, 2007.

CARVALHO, Weliton. Direito Comparado. Método ou ciência? Revista de informação legislativa. Brasília: Senado Federal, Subsecretaria de Edições Técnicas, n º180, 2008

COMISSÃO INTERAMERICANA DE DIREITOS HUMANOS. Informe $\mathrm{n}^{\circ}$ 28/92. Casos $10.147,10.181,10.240,10.262,10.309$ y 10.311. Argentina. 2 de octubre de 1992. Disponível em: <https://www.cidh.oas.org/annualrep/92span/Argentina10.147.htm>. Acesso em: 31 jan. 2017-A.

COMISSÃO INTERAMERICANA DE DIREITOS HUMANOS. Informe 70/99. Caso 12.059, Carmen Aguiar de Lapacó, 4 de mayo de 1999. Disponível em:

<https://www.cidh.oas.org/annualrep/99span/Admisible/Argentina12.059.htm>. Acesso em: 31 jan. 2017-B.

CORTE INTERAMERICANA DE DIREITOS HUMANOS. Caso Barrios Altos Vs. Perú. Fondo. Sentencia de 14 de marzo de 2001. Serie C No. 75. Parágrafo 41. Disponível em: <http://www.corteidh.or.cr/docs/casos/articulos/Seriec_75_esp.pdf>. Acesso: 24 jun. 201-A.

CORTE INTERAMERICANA DE DIREITOS HUMANOS. Caso Ivcher Bronstein vs. Perú. Competencia. Sentencia del 24 de septiembre de 1999, Serie C, n. ${ }^{\circ}$ 54; Corte Interamericana de Derechos Humanos. Caso del Tribunal Constitucional vs. Perú, competencia. Sentencia del 24 de septiembre de 1999, Serie C, n. ${ }^{\circ}$ 55. Disponível em:

<http://www.corteidh.or.cr/docs/casos/articulos/Seriec_75_esp.pdf>. Acesso: 24 jun. 2016-B.

CORTE INTERAMERICANA DE DIREITOS HUMANOS. Informe 21/00. Caso 12.059, Carmen Aguiar de Lapacó, 29 de febrero de 2000. Disponível em:

<http://www.cidh.org/annualrep/99span/Soluci\%C3\%B3n\%20Amistosa/Argentina12059.htm>. Acesso em: 31 jan. 2017-A.

CORTE INTERAMERICANA DE DIREITOS HUMANOS. Resolución de la Corte Interamericana de Derechos Humanos de 22 de septiembre de 2005. Caso Barrios Altos. Cumplimiento de sentencia. Disponível em:

<www.corteidh.or.cr/docs/supervisiones/barrios_22_09_05.doc>. Acesso em: 31 jan. 2017-B.

DANTAS, Ivo. Direito Constitucional Comparado: introdução. Teoria e metodologia. $2^{\mathrm{a}}$ ed. Rio de Janeiro: Renovar, 2006.

DOEHRING, Karl. Teoria do Estado. Belo Horizonte: Del Rey, 2008. 
DOUZINAS, Costas. O fim dos direitos humanos. São Leopoldo: Unisinos, 2009.

DURKHEIM, David Émile. As regras do método sociológico. São Paulo: Editora nacional, 1985.

ENGSTROM, Par. A Anistia e o Sistema Interamericano de Direitos Humanos. In: A anistia na era da responsabilização: o Brasil em perspectiva internacional e comparada. PAYNE, Leigh A; ABRÃO, Paulo; TORELLY, Marcelo D. Brasília: Ministério da Justiça, Comissão de Anistia; Oxford: Oxford University, Latin American Centre, 2011.

FERNADES, Florestan. Fundamentos empíricos da explicação sociológica. São Paulo: T. A. Queiroz, 1980.

FERREIRA, Pinto. Sociologia. 2a ed. Recife: Companhia Editora de Pernambuco, 1969.

HUNTER, Wendy. Continuity or Change? Civil-Military Relations in Democratic Argentina, Chile, and Peru. Political Science Quarterly, Vol. 112, No. 3 (Autumn, 1997), p. 453-475.

JOLIVET. Régis. Tratado de filosofia I: Introdução geral lógica - cosmologia. Rio de Janeiro: Livraria Agir Editora, 1969.

KOENIG, Samuel. Elementos de sociologia. 2a ed. Rio de Janeiro: Zahar editores, 1970.

MEZA, Miguel Arenas. La contribución de la jurisprudencia de la Corte Interamericana de Derechos Humanos a la eliminación de las "Leyes de Amnistía" en América Latina: un paso decisivo en la lucha contra la impunidad. Rey Tristán, Eduardo; Calvo González, Patricia. XIV Encuentro de Latinoamericanistas Españoles: congreso internacional, Sep 2010, Santiago de Compostela, España. Universidade de Santiago de Compostela, Centro Interdisciplinario de Estudios Americanistas Gumersindo Busto; Consejo Español de Estudios Iberoamericanos, pp.2175-2189, 2010.

Militares ficam sem anistia: Até Mário Covas votou contra reintegração de cassados. Medo de golpe foi a desculpa. Política. Correio Brasiliense. 17 nov. 1987.

MORALES, Ethel Nataly Castellanos. Verdad, justicia y reparación en Argentina, El Salvador y Sudáfrica. Estud. Socio-Juríd., Bogotá (Colombia), 7 (Número especial), agosto de 2005, pp. 200-249.

NINO, Carlos Santiago. Juicio al mal absoluto: ?Hasta donde debe llegar la justicia retroactiva en casos de violaciones masivas de los derechos humanos? $1^{a}$ ed. Buenos Aires: Siglo Veintiuno Editores, 2015.

PEREIRA, Caio Mário da Silva. Direito Comparado e seu estudo. Revista da Faculdade de Direito de Minas Gerais, 1955. 
PERRONE-MOISÉS, Cláudia. Lei de anistia face ao Direito Internacional: "Desaparecimentos" e "direito à verdade". In: PIOVESAN, Flávia (coord.). Direitos Humanos, Globalização Econômica e Integração Regional. São Paulo: Max Limonad, 2002, pp. 285-305.

PERU. Congreso de la República. Ley no 26.479. Disponível em: <http://www.congreso.gob.pe/ntley/Imagenes/Leyes/26479.pdf>. Acesso em: 11 jul. 2016. A

PERU. Congreso de la República. Congreso de la República. Ley n ${ }^{\circ} 26.492$. Disponível em: <http://www.congreso.gob.pe/ntley/Imagenes/Leyes/26492.pdf>. Acesso em: 11 jul. 2016. B

SCHNEIDER, Sérgio; SCHMITT, Cláudia Job. O uso do método comparativo nas ciências sociais. Caderno de Sociologia. Porto Alegre: v. 9, p. 49 - 87, 1998.

SERRANO, Pablo Jiménez. Como utilizar o direito comparado para elaboração de tese científica. Rio de janeiro: Forense, 2006.

SMULOVITZ, Catalina. Constituición y poder judicial en la nueva democracia Argentina. La experiencia de las instituciones. In.: ACUÑA, Carlos (comp.). La nueva matriz politica Argentina. Buenos Aires: Ediciones Nueva Visión, 1995.

SOUTO, Cláudio. Da inexistência científico-conceitual do Direito Comparado: conceituação do indagar comparativo mais específico da Ciência do Direito. Recife: [s.n.], 1956.

TAVARES, Ana Lúcia de Lyra. Notas sobre as dimensões do direito constitucional comparado. Revista brasileira de direito comparado. Rio de Janeiro: Instituto de Direito Comparado Lusobrasileiro, 2009.

TRINDADE, Cançado A. A. Voto concordante do Juiz A. A. Cançado Trindade. In Revista do Instituto Brasileiro de Direitos Humanos, 2002.

TRINDADE, Vinícius Fox D. Cançado. Resenha: per non dementicare - uma análise das leis de auto-anistia na evolução jurisprudencial da Corte Interamericana de Direitos Humanos. Revista do Instituto Brasileiro de Direitos Humanos. Fortaleza, vol. 8, nº 8, p. 281 - 292, 2008, p. 281. 